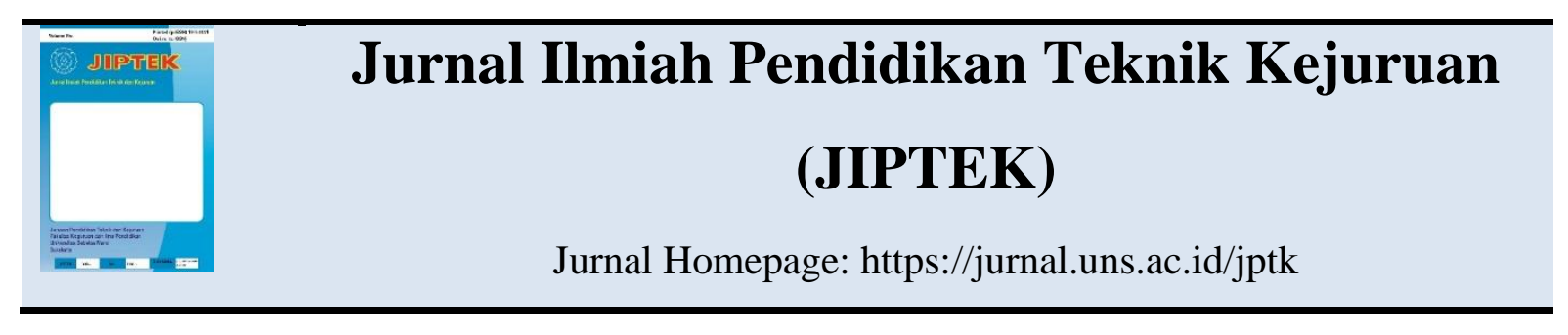

\title{
PENGARUH INHIBITOR BLIMBING WULUH TERHADAP PENGENDALIAN KOROSI BAJA KARBON DALAM LARUTAN NaCl
}

\author{
Nyenyep Sriwardani ${ }^{1}$, Ranto $^{2}$, Ngatau Rohman ${ }^{3}$, Basori $^{4}$ \\ 1,2,3,4Program Studi Pendidikan Teknik Mesin, FKIP, Universitas Sebelas Maret Surakarta \\ Jalan Ahmad Yani 200 Surakarta \\ Email: daniptm@yahoo.com
}

\begin{abstract}
ABSTRAK
Dewasa ini meskipun pengolahan bahan plastik, polimer, keramik dan non logam lainnya sudah menunjukkan kekuatan yang memadai, akan tetapi penggunaan baja karbon masih memiliki prosentase yang besar dalam bidang konstruksi dan perkapalan. Kelemahan dari baja karbon adalah terjadi oksidasi dengan udara yang disebut dengan timbulnya karat besi. Terjadinya korosi pada dapat mengakibatkan ketahanan dari suatu peralatan menjadi menurun sehingga mudah terjadi kerusakan. Proses korosi dapat terjadi lebih cepat pada daerah lembab dan ber-air, untuk itu perlu dilakukan pencegahan supaya perkakas atau peralatan industri dengan bahan dasar baja dapat awet. Pada penelitian ini adalah sebuah studi terhadap baja karbon yang diberi lapisan asam dari blimbing wuluh kemudian dimasukkan ke dalam larutan $\mathrm{NaCl}$. Sebagai pembanding percobaan juga dilakukan dengan menggunakan aquades cair. Pengamatan dilakukan untuk mengetahui bagaimana efek blimbing wuluh sebagai eco inhibitor terhadap baja pada larutan $\mathrm{NaCl}$.
\end{abstract}

Kata kunci: inhibitor, eco inhibitor, blimbing wuluh, baja karbon, $\mathrm{NaCl}$.

\begin{abstract}
Nowadays although the processing of plastic, polymer, ceramic and other non-metal materials has shown sufficient strength, the use of carbon steel still has a large percentage in the field of construction and shipping. The disadvantage of carbon steel is that there is oxidation with air, which is called iron rust. Corrosion can result in a decrease in the resistance of an equipment so that damage can easily occur. The corrosion process can occur faster in humid and watery areas, so it is necessary to prevent so that the tools or industrial equipment with steel-based materials can last. In this study, a study of carbon steel which was given an acid layer from the starch was then put into $\mathrm{NaCl}$ solution. As a comparison the experiments were also carried out using liquid distilled water. Observations were made to find out how the effect of averrhoa bilimbi as an eco inhibitor on steel in $\mathrm{NaCl}$ solution.
\end{abstract}

Keywords: inhibitors, eco inhibitors, averrhoa bilimbi, carbon steel, $\mathrm{NaCl}$ 
PENDAHULUAN

Pengaruh dari lingkungan dapat membuat suatu produk yang terbuat dari logam tidak dapat mempertahankan kondisi idealnya. Hal tersebut disebabkan terjadi perubahan sifat dan struktur pada material sehingga mengalami penurunan kinerja atau kegagalan. Menurut teori ada beberapa tipe kegagalan yaitu: kegagalan akibat korosi, perpatahan tertunda atau lazimnya disebut fatik, kegagalan pada suhu tinggi atau akibat lingkungan sekitar, dan kegagalan akibat radiasi yang merusak suatu material atom demi atom dan elektron demi elektron, dan masih banyak lagi. Korosi adalah suatu proses deteriorasi permukaan logam. Apabila lingkungan kurang mendukung maka laju korosi dapat dikendalikan antara lain dengan mengisolasi permukaan logam dari lingkungannya.

\section{METODOLOGI PENELITIAN}

Tujuan dari penelitian adalah untuk mengetahui pengaruh asam pada permukaan baja karbon yang berada di dalam aquades liquid dan untuk mengetahui pengaruh asam pada permukaan baja karbon yang berada di dalam larutan $\mathrm{NaCl}$.

Penelitian ini termasuk dalam kategori experimental research, yaitu melakukan percobaan dan pengamatan untuk mendapatkan data penelitian yang sahih melalui 4 kondisi percobaan, yaitu:

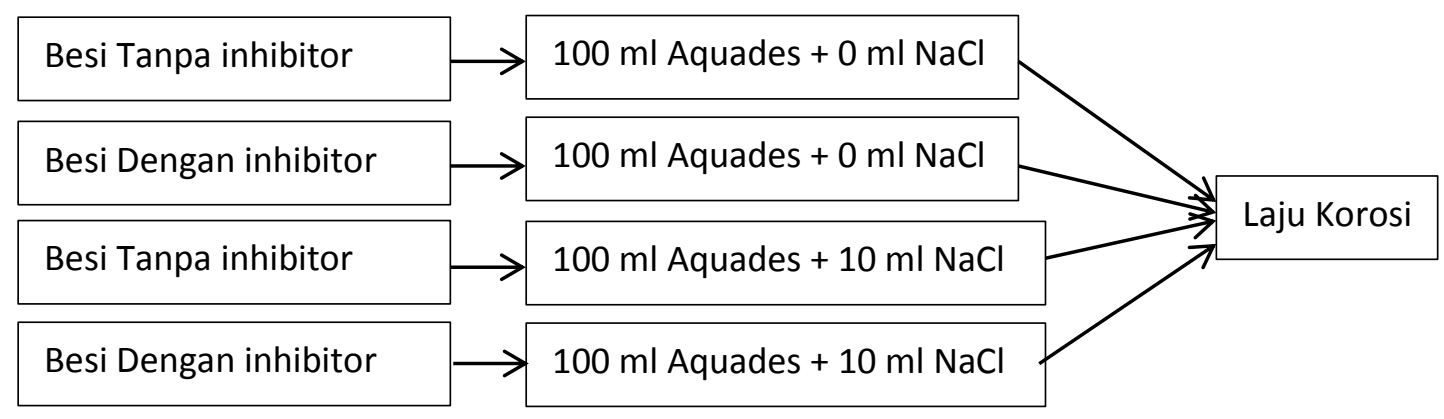

Gambar 1. Konsep penelitian

Untuk mengetahui pengaruh dari bio-inhibitor yang berasal dari blimbing wuluh maka dilakukan pengamatan pada 4 kondisi yang berbeda. Yang pertama adalah besi (baja karbon) yang dimasukkan ke dalam aquades murni. Pada kondisi kedua besi dilapisi terlebih dahulu dengan air blimbing wuluh yang dimaksudkan sebagai inhibitor. Kondisi ketiga dan ke empat sama dengan pertama dan kedua, akan tetapi larutan yang digunakan adalah aquades ditambah dengan $\mathrm{NaCl} 10 \mathrm{ml}$ pada $100 \mathrm{ml}$ aquades. Setelah 7 hari diamati perubahan yang terjadi. 
HASIL PENGAMATAN

Setelah besi (baja karbon) berada dalam cairan maka mulai menunjukkan perubahan warna pada bagian permukaannya sehingga tampak seperti penampilan gambar 2 .
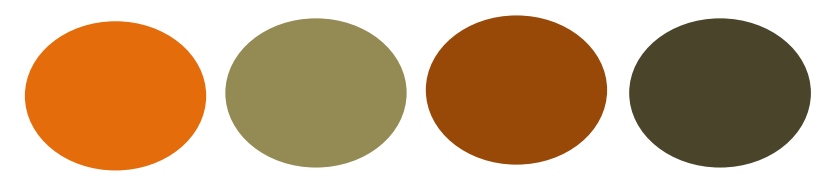

Gambar 2. Permukaan baja karbon setelah berada di dalam aquades dan larutan aquades + Natrium Clorida

Sedangkan pada permukaan penguapan larutan aquades dan $\mathrm{NaCl}$ dinding kaca tempat wadah cairan menepel terdapat kristal-kristal garam yang tersisa karat-karat besi yang tertinggal setelah disamping perubahan warna dinding akibat aquades menguap. Sementara itu pada proses korosi logam.
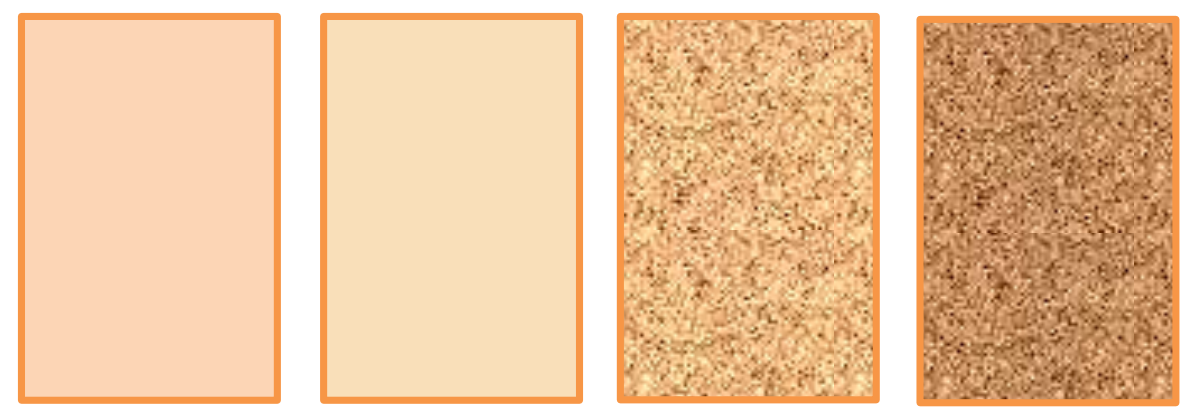

Gambar 3. Permukaan dinding gelas setelah cairan menguap 
PEMBAHASAN

\section{BESI DALAM AQUADES}

Peristiwa yang terjadi pada kondisi 1 (satu), korosi yang terjadi adalah proses elektrokimia. Pada daerah anodik besi atau daerah permukaan yang bersentuhan dengan tetesan air mengalami pelarutan atomatom disertai dengan pelepasan elektron membentuk ion $\mathrm{Fe}^{2+}$ yang larut dalam air.

$$
\mathrm{Fe}_{(s)} \rightarrow \mathrm{Fe}^{2+}{ }_{(a q)}+2 e^{-}
$$

Kemudian elektron yang dilepaskan mengalir melalui besi, menuju daerah katodik hingga terjadi reduksi gas oksigen dari udara.

$$
\mathrm{O}_{2(g)}+2 \mathrm{H}_{2} \mathrm{O}_{(g)}+2 e^{-} \rightarrow 4 \mathrm{OH}^{-}(a q)
$$

Ion $\mathrm{Fe}^{2+}$ yang larut dalam tetesan air bergerak menuju daerah katodik dan bereaksi dengan ion-ion $\mathrm{OH}^{-}$membentuk $\mathrm{Fe}(\mathrm{OH})_{2}$,

$$
\begin{gathered}
\mathrm{Fe}_{(a q)}^{2+}+4 \mathrm{OH}_{(a q)}^{-} \rightarrow \mathrm{Fe}(\mathrm{OH})_{2(s)} \\
\mathrm{Fe}(\mathrm{OH})_{2} \text { yang terbentuk }
\end{gathered}
$$

dioksidasi lanjut oleh oksigen membentuk karat.

$$
\begin{aligned}
2 \mathrm{Fe}(\mathrm{OH})_{2(s)} & +\mathrm{O}_{2(\mathrm{~s})} \\
& \rightarrow \mathrm{Fe}_{2} \mathrm{O}_{3} \cdot \mathrm{nH}_{2} \mathrm{O}_{(\mathrm{s})}
\end{aligned}
$$

Reaksi keseluruhan adalah sebagai berikut:

$$
\begin{aligned}
& 4 \mathrm{Fe}_{(s)}+3 \mathrm{O}_{2(s)}+n \mathrm{H}_{2} \mathrm{O}_{(l)} \\
& \rightarrow 2 \mathrm{Fe}_{2} \mathrm{O}_{3} \cdot n \mathrm{H}_{2} \mathrm{O}_{(s)} \quad \text { Karat }
\end{aligned}
$$

Terbentuknya karat menyebabkan air dan permukaan besi berubah warna menjadi kekuningan.
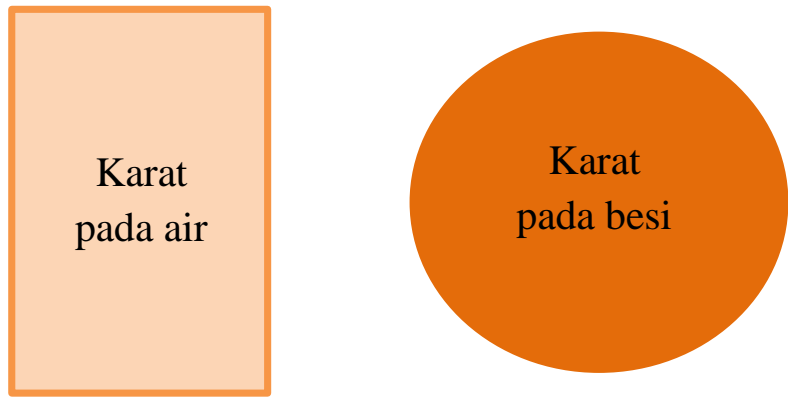

Gambar 4. Oksidasi pada $\mathrm{Fe}(\mathrm{OH})_{2}$ 
2. BESI DENGAN INHIBITOR DALAM AQUADES

Besi yang bersentuhan dengan air akan mengalami pelarutan atomatom yang disertai dengan pelepasan elektron membentuk ion $F e^{2+}$ yang larut dalam air.

$$
\mathrm{Fe}_{(s)} \rightarrow \mathrm{Fe}^{2+}(a q)+2 e^{-}
$$

Elektron yang dilepaskan mengalir melalui besi, sebagaimana elektron mengalir melalui rangkaian luar pada sel volta, menuju daerah katodik hingga terjadi reduksi gas oksigen dari udara.

$$
\mathrm{O}_{2(g)}+2 \mathrm{H}_{2} \mathrm{O}_{(g)}+2 e^{-} \rightarrow 4 O \mathrm{H}^{-}(a q)
$$

Inhibitor yang bersifat asam dan bermuatan positif bereaksi dengan $\mathrm{OH}_{(a q)}^{-}$sehingga ion $\mathrm{Fe}^{2+}$ tidak bereaksi membentuk karat pada besi.

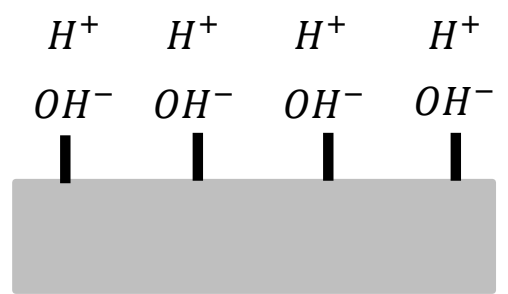

Gambar 5. Reduksi gas oksigen dari udara menghasilkan $\mathrm{OH}^{-}$pada permukaan besi kemudian terhalang $H^{+}$pada permukaan logam.

\section{BESI DALAM AQUADES $+\mathrm{NaCl}$}

Besi yang berada di dalam larutan mengandung garam dapur
$(\mathrm{NaCl})$ lebih cepat mengalami korosi dibandingkan dengan besi yang berada di dalam aquades.
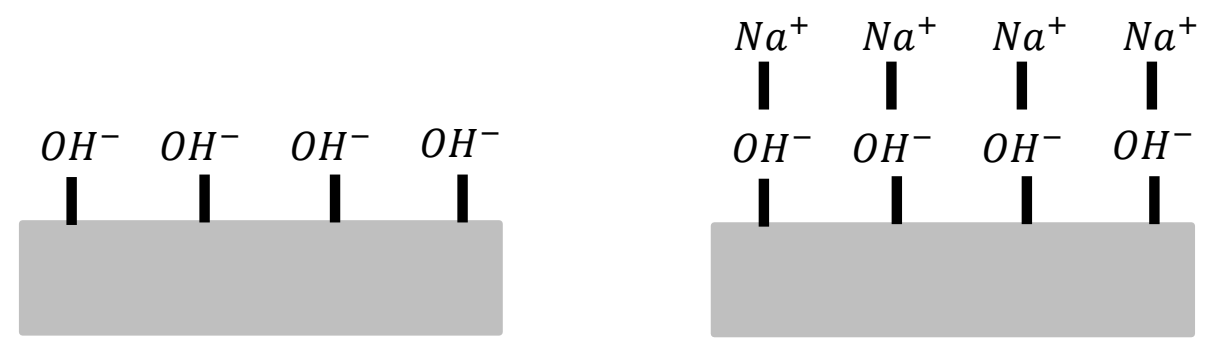

Gambar 3.6. Reduksi gas oksigen dari udara menghasilkan $\mathrm{OH}^{-}$pada permukaan besi kemudian bereaksi dengan $\mathrm{Na}^{+}$

Setiap 2 atom $\mathrm{Na}^{+}$berikatan dengan 2 molekul $\mathrm{OH}^{-}$maka 2 atom $\mathrm{Cl}^{-}$akan berikatan dengan 2 atom $H^{+}$ menghasilkan 1 molekul $\mathrm{O}_{2}$ bebas yang akan bereaksi dengan $\mathrm{H}_{2} \mathrm{O}$ membentuk
4 molekul $\mathrm{OH}^{-}$. Sehingga korosi berlangsung 2 kali lebih cepat daripada besi yang berada dalam aquades. 
4. BESI DENGAN INHIBITOR

DALAM AQUADES + $\mathrm{NaCl}$

Karena permukaan logam terlapisi oleh $\mathrm{H}^{+}$maka terjadi reaksi seperti elektrolisis larutan Natrium klorida. Dimana terbentuk endapan $\mathrm{NaOH}$ yang lebih banyak.

\section{KESIMPULAN}

Kesimpulan dari penelitian ini yaitu, proses korosi terjadi lebih cepat pada larutan $\mathrm{NaCl}$. Adapaun proses berlangsungnya mekanisme kerja dari inhibitor korosi pada logam adalah sesuai dengan teori yaitu:

1. Inhibitor teradsorpsi pada permukaan logam membentuk suatu lapisan pelindung dengan ketebalan beberapa molekul inhibitor.

2. Inhibitor dapat mengendap dan teradsorpsi pada permukaan logam.

3. Logam terlebih dahulu terkorosi, kemudian ion-ion logam bereaksi dengan inhibitor menghasilkan senyawa kompleks teradsorpsi pada permukaan logam, membentuk suatu lapisan pasif (pasivasi).

4. Inhibitor menghilangkan atau menangkap (scavenger) zat korosif dari lingkungannya sehingga lingkungan menjadi tidak atau kurang korosif.
Permukaan baja karbon yang diberi Blimbing wuluh mengalami reaksi sehingga secara visual dapat dilihat terjadinya perubahan warna menjadi lebih cerah pada larutan aquades dan lebih gelap pada larutan $\mathrm{NaCl}$. Sedangkan pada dinding gelas percobaan terdapat endapan yang lebih sedikit.

\section{DAFTAR PUSTAKA}

A.Keyvani, M.Yeganeh, H. Rezaeyan. 2017. Application of mesoporous silica nanocontainers as an intelligent host of molybdate corrosion inhibitor embedded in the epoxy coated steel. Journal Progress in Natural Science: Materials International. Vol. 27. Pp. 261-267.

Sunarya, Y. 2016. Kimia Dasar 2: Berdasarkan Prinsip-Prinsip Kimia Terkini. Yrama Widya: Bandung. 